\title{
Cultura de PaZ e ações sócio-eduCativas: Desafios PaRa a escola ConteMPorânEa
}

Leila Dupret $^{1}$

\begin{abstract}
A paz não pode ser apenas garantida pelos acordos políticos, econômicos ou militares. No fundo, ela depende do comprometimento unânime, sincero e sustentado das pessoas. Cada um de nós, independentemente da idade, do sexo, do estrato social, crença religiosa ou origem cultural é chamado à criação de um mundo pacificado ${ }^{2}$.
\end{abstract}

As palavras do Diretor Geral da UNESCO, Kö̈chiro Matsuur, pretendem mostrar a necessidade e importância de estarmos engajados no movimento pela Paz, construindo uma Cultura que permita conjugar atitudes individuais e coletivas em prol do bemestar dos cidadãos e do desenvolvimento humano.

Mas, o que significa Cultura da Paz?

Construir uma cultura da paz envolve dotar as crianças e os adultos de uma compreensão dos princípios e respeito pela liberdade, justiça, democracia, direitos humanos, tolerância, igualdade e solidariedade. Implica uma rejeição, individual e coletiva, da violência que tem sido parte integrante de qualquer sociedade, em seus mais variados contextos. A cultura da paz pode ser uma resposta a diversos tratados, mas tem de procurar soluções que advenham de dentro da (s) sociedade (s) e não impostas do exterior.

Cabe ressaltar que o conceito de paz pode ser abordado em seu sentido negativo, quando se traduz em um estado de não-guerra, em ausência de conflito, em passividade e permissividade, sem dinamismo próprio; em síntese, condenada a um vazio, a uma não existência palpável, difícil de se concretizar e precisar. Em sua concepção positiva, a paz não é o contrário da guerra, mas a prática da não-violência para resolver conflitos, a prática do diálogo na relação entre pessoas, a postura democrática frente à vida, que pressupõe a dinâmica da cooperação planejada e o movimento constante da instalação de justiça.
Uma cultura de paz implica no esforço para modificar o pensamento e a ação das pessoas no sentido de promover a paz. Falar de violência e de como ela nos assola, deixa de ser a temática principal. Não que ela vá ser esquecida ou abafada; ela pertence ao nosso dia-a-dia e temos consciência disto. Porém, o sentido do discurso, a ideologia que o alimenta, precisa impregná-lo de palavras e conceitos que anunciem os valores humanos que decantam a paz, que lhe proclamam e promovem. A violência já está bastante denunciada, e quanto mais falamos dela, mais lembramos sua existência em nosso meio social e ambiental. É hora de começarmos a convocar a presença da paz em nós, entre nós, entre nações, entre povos.

Um dos primeiros passos neste sentido, refere-se à gestão de conflitos. Ou seja, prevenir os conflitos potencialmente violentos e reconstruir a paz e a confiança entre pessoas emergentes de situação de guerra, é um dos exemplos mais comuns a serem considerados. Tal missão estende-se às escolas, instituições e outros locais de trabalho por todo o mundo, bem como aos parlamentos e centros de comunicação, a lares e associações.

O conflito é um processo natural e necessário em toda sociedade humana, é uma das forças motivadoras da mudança social e um elemento criativo essencial nas relações humanas ${ }^{3}$.

Um outro passo é tentar erradicar a pobreza e reduzir as desigualdades, lutando para atingir um desenvolvimento sustentado e o respeito pelos direitos humanos, reforçando as instituições democráticas, promovendo a liberdade de expressão, preservando a diversidade cultural e o ambiente.

A cultura da paz está pautada em valores humanos que precisam ser colocados em prática, a fim de passarem do estado de intenção para o exercício da ação,

\footnotetext{
${ }^{\top}$ Docente da Universidade Estácio de Sá

${ }^{2}$ Clara, I. S. \& Silva, M. M. (2000). Por uma pedagogia para a não violência. Porto: Profedições, 4.

${ }^{3}$ El conflicto es un processo natural y necesario en toda sociedad humana, es una de las fuerzas motivadoras del cambio social y un elemento creativo esencial en las relaciones humanas. Arenal apud Jares, 1999, 110.
} 
transformando-se, concretamente, em atos. Tais valores, que se traduzem em éticos, morais e estéticos, nos encaminham para o despertar de expressões de amor e manifestações de respeito, que têm estado adormecidas, nos últimos tempos.

Os homens, ao definirem sua posição em relação ao amor, tradicionalmente têm definido também sua posição diante da vida, daí a importância do mesmo, já que esta necessidade claramente humana não se expressa exclusivamente no amor conjugal ... mas inclui, além disso, o amor aos filhos, aos pais, aos amigos, à pátria e outras formas de manifestação desse afeto que se encontra na base do comportamento humano. ${ }^{4}$

$\mathrm{O}$ amor, em seus diversos modos, vem sendo relegado a um segundo plano, pelas pessoas que acabam priorizando a necessidade de obter êxito em seu trabalho ou de resolver as dificuldades da vida diária. $\mathrm{O}$ que tem provocado, por uma lado, ignorar o próprio potencial que temos para amar, e por outro, minimizar sua importância. Mostrar, livre e sem inibição, nossa capacidade de amar tem sido uma tarefa das mais difíceis, atualmente.

Isto porque, idiosincrasias e identidades nacionais, além de influências sociais, acrescidas da idade, sexo, escolaridade, ocupação e outros constituintes da especificidade psicológica de cada um, repercutem sobre o modo como assumimos o amor. Assim, ele pode ser considerado como uma parte especial da cultura contemporânea, na qual encontram-se uma série de valores, atitudes e formas de comportamento.

$\mathrm{O}$ amor é um sentimento que se caracteriza por envolver a personalidade como um todo, traduzindo-se em valorização pessoal e auto-estima. Ou seja, se converte em um motor que impulsiona e regula a conduta de alguém no sentido de compelir à realização ou propor coisas que antes não eram sequer cogitadas.

Obviamente, não podemos perder de vista nosso contexto atual, pois, não há dúvida, que os processos de automação, a velocidade do cotidiano e, de um modo geral, os complexos e ameaçadores tempos que vivemos, estão latentes em nossa subjetividade e possuem um valor estressante, modificando a atitude e concepção do fenômeno amoroso. A isto se juntam velhos vícios que, ainda hoje, permeiam a educação e a orientação que os pais dão aos filhos, educando a menina e o menino com padrões psicológicos e morais totalmente diferentes. O que acaba se estendendo aos contextos escolares e funcionando como impedidores da manifestação do amor em sua versão mais simples.

Compreendemos que é imprescindível que os meios de comunicação maciça, as escolas e universidades, assim como todos os que, a título individual ainda acreditam na necessidade deste sentimento, divulguem-no, educando e propagando-o sob formas de intercâmbio e comunicação entre casais, entre pais e filhos, com o resto da família e a sociedade em geral. O amor, entendido como um componente essencial da cultura é, não só, causador de um desfrute estético para quem o possui, como também provoca o bem-estar físico, psíquico e social, transformando-se em um poderoso meio promotor de saúde e autodesenvolvimento humano.

É então no entrelaçamento paz - desenvolvimento - direitos humanos - democracia, que podemos vislumbrar a Educação para a Paz.

... Um processo educativo, dinâmico, contínuo e permanente, fundamentado no conceito de paz positiva e na perspectiva criativa do conflito, como elementos significantes e definidores, e que, através da aplicação de enfoques sócio-afetivos e problematizantes, pretende desenvolver um novo tipo de cultura, a cultura de paz, que ajude as pessoas a desvelar criticamente a realidade para poder situar-se frente a ela e, conseqüentemente, atuar.

\section{Complexidade e Transdisciplinaridade}

O paradigma da complexidade ... incita a distinguir e fazer comunicar, em vez de isolar e de separar, a reconhecer os traços singulares, originais, históricos dos fenômenos, em vez de ligá-los pura e simplesmente a determinações ou leis gerais, a conceber a unidade-multiplicidade de toda entidade, em vez de a heterogeneizar em categorias separadas ou de a homogeneizar em indistinta totalidade.

As palavras de Morin nos levam a refletir sobre a necessidade de serem pensados, cientificamente e com consciência, os princípios que regem nossas práticas, seja em pesquisa ou estudos, seja no cotidiano. Um outro olhar está convocado a ser posto sobre o que fazemos ou investigamos.

\footnotetext{
${ }^{4}$ Los hombres, al definir su posición en relación com el amor tradicionalmente, han definido tambiém su posición ante la vida, de ahí la importancia del mismo, ya que esta necesidad netamente humana no se expresa exclusivamente en el amor de pareja ... sino que incluye además, el amor a los hijos, a los padres, a los amigos, a la patria y otras formas de manifestación de esse afecto que se encuentra en la base del comportamiento humano. Ortiz, F. C. \&Ortiz, R.P. (2001). Amor vs amor. Cuba: Ed. Puebloy Educación, 4.
} 
Alguns componentes deste desafio, e que podem ser nominados de Constituintes da Complexidade, são fundamentais para o nosso propósito imediato. A começar queremos chamar a atenção para a insuficiência do Princípio da Universalidade, que, partindo de concepções generalizadoras, estabelece como referência o que é homogêneo, nivelando e criando padrões a serem seguidos e ou acreditados como definitivos, sem que a relação espaço-temporal tenha qualquer relevância. Por outro lado, impede que sejam consideradas as diferenças como informações importantes e necessárias, para dedicar-lhe o status de insuficientes ou anômalas.

Não podemos mais deixar de ter em conta a referência e a interferência da história e seu percurso; os atravessamentos sócio-culturais, político-econômicos não só pertencem, como integram a constituição e o desenvolvimento humanos. Logo, nos deparamos com a impossibilidade utilizar apenas o universal como parâmetro, pois que o dado singular também marca a sua presença. Em uma palavra, universal e singular coexistem. Assim, torna-se impraticável isolar unidades, pois elas já são dotadas de multiplicidade.

Seguindo esta diretriz, podemos perceber que a relação causal de condução linear, ou seja, a premissa "se isto, então aquilo", dá lugar a uma outra lógica de pensamento regida pelo princípio da endoexocausalidade. Isto é, a ênfase está no que se constrói a partir da relação entre o que é interno, individual, e o que é externo, coletivo. Assim, o critério de previsibilidade que oferece condição para a ciência controlar os fenômenos, necessariamente tropeça na imprevisibilidade que se efetiva como fato. E acontecimentos inesperados se colocam como pregnantes e indispensáveis de serem analisados.

Tais pressupostos viabilizam abordar a diversidade cultural em bases que acompanham o rigor de qualquer estudo científico, sem engessá-la ou tentar enquadrá-la em modelos tradicionalmente instituídos como dotados de credibilidade. Para o ser humano, ainda que pareça uma aventura, passa a ser condição "sine qua non" reconhecer-se em sua humanidade e, ao mesmo tempo, reconhecer a diversidade cultural inerente a tudo o que é humano. Deste modo, ele é singular e múltiplo em sua existência.

Os que vêem a diversidade das culturas tendem a minimizar ou a ocultar a unidade humana; os que vêem a unidade humana tendem a considerar como secundária a diversidade das culturas. Ao contrário, é apropriado conceber a unidade que assegure e favoreça a diversidade, a diversidade que se inscreve na unidade. ${ }^{5}$

Responder a pergunta sobre "Quem somos?" não pode estar separado de onde estamos, de onde viemos e para onde vamos. Em outras palavras, a unidade humana não está só no fato de pertencer à espécie e a diversidade humana não se encontra apenas nos conteúdos psicológicos, culturais, sociais, políticos, religiosos, mas é no movimento de entrelaçar todos os componentes que se constrói a rede interativa característica do desenvolvimento, verdadeiramente, humano.

O ponto de partida de que falamos, pressupõe uma maneira de funcionar que possa legitimar sua proposta, estabelecendo métodos de proceder que unam a suposta teoria com a prática. Obviamente, este outro modo de perceber o ser humano carece de uma metodologia para abordá-lo e, por extensão o seu entorno, que leve em conta o que está para além de cada uma destas instâncias. Ou seja, ter a visibilidade do que transcende uma e outra, não sendo possível estudar separadamente cada facção, ou mesmo imprimir como determinante alguma das partes. Em uma palavra, utilizar a perspectiva transdisciplinar.

Lançando mão do velho exemplo culinário para ilustrar o que dizemos, vamos descascar algumas frutas (banana, laranja, mamão e pêra, por exemplo), cortá-las em pedaços e colocá-las em um recipiente. Ao misturá-las, temos uma salada de frutas. Esta sobremesa, de sabor próprio, mantém seus constituintes reconhecíveis e, caso não se goste de alguma das frutas, podemos separá-la, e não comê-la. Caracterizamos com isto, a possibilidade de desconsiderar algo que pertence ao prato servido, ou priorizar uma parte para saborear.

Agora, em vez de misturar os pedaços de frutas em um recipiente, vamos colocá-los no copo do liqüidificador e ligá-lo, fazendo uma vitamina. O que podemos constatar? A composição é outra e apresenta um novo sabor. As frutas que lá estão e que permanecem sendo as que coloquei na mistura anterior (banana, laranja, mamão e pêra, por exemplo), estão entrelaçadas de tal forma que não é possível separálas, eliminar alguma delas, ou priorizar qualquer uma das partes que constitui o composto, que é único e múltiplo a um só tempo. As frutas estão para além delas mesmas, transcendendo uma a outra. 
Com tal ilustração pretendemos apontar que a transdisciplinaridade se mostra como uma perspectiva metodológica possível para estudarmos o ser humano em sua amplitude, porque ela nos permite abordá-lo em sua complexidade, considerando a coexistência do que é individual e coletivo, singular e plural, específico e geral, respeitando a rede de interações que constituem a teia da própria vida.

\section{Ações Sócio-Educativas}

O princípio que inspira as ações sócio-educativas parte do reconhecimento das diferenças entre pessoas e grupos. Ele vai nos dar a chave para realizar uma ação conjunta com todas as partes implicadas, para efetuar mudanças que incidam sobre a melhora da qualidade de vida. Fomentando a consciência crítica e favorecendo a transformação social, o processo educativo passa a ser responsabilidade não só das pessoas diretamente envolvidas com ele (pais e filhos, professores e alunos...), mas também da comunidade a que pertencem. Intervenção que teria como finalidade possibilitar e promover estilos de vida alternativos, que favoreceriam o crescimento pessoal, tanto individual como o coletivo, ajudando e apoiando os menores e os jovens a realizar eleições responsáveis positivas e críticas. ${ }^{6}$

A implantação de ações sócio-educativas deve envolver mulheres e homens de todos os níveis da sociedade numa larga e cruzada rede de atividades, que permitam colocar em prática os pressupostos teóricos e os princípios metodológicos que regem a Cultura de Paz.

As bases que alicerçam as ações sócio-educativas estão voltadas a:

- Identificar formas de violência.

- Adquirir hábitos de discussão e posicionamento crítico em relação às realidades sociais passadas e atuais.

- Desenvolver o espírito de tolerância e a capacidade de diálogo.

- Construir um quadro de valores humanistas em que a solidariedade surja como suporte lógico de todos os comportamentos individuais e coletivos.

- Desenvolver atitudes de solidariedade em relação ao "outro": indivíduo, povo, cultura.

- Adquirir hábitos de discussão e posicionamento crítico face a outros povos.
- Identificar situações de violação dos direitos humanos.

- Identificar as "justificativas" para atentados à liberdade individual e refletir sobre as mesmas.

- Contribuir para a conscientização do papel de cada um e de todos no combate às diferentes formas de discriminação.

- Identificar meios e profissionais da comunicação social que servem à defesa dos direitos dos cidadãos.

- Identificar indicadores de violência

- Relacionar o saber científico com as vivências sociais

- Promover hábitos de pesquisa

- Clarificar conceitos

A Educação para a Paz está - tem de estar presente em todas as palavras, todas as atitudes, todos os momentos de todos os dias.

Como podem as idéias e os ideais ligados pela expressão "Cultura de Paz" serem transformados em políticas e ações, públicas e privadas, que mudem as vidas, onde quer que elas sejam ou estejam?

Esta pergunta, que nos inquieta a todos, pode ser respondida com sugestões a serem exercidas na prática educativa, que têm como principal argumento as informações advindas do cotidiano. Tais ações, tipicamente sócio-educativas, estão pautadas na singularidade do desenvolvimento humano sustentado pela interação sujeito-mundo, a qual nos permite compreender a proposta pedagógica de Paulo Freire, por um lado, e as concepções psicológicas de Vigotski, por outro, proporcionando uma interpenetração pertinente à visão transdisciplinar.

A ação educativa de alfabetizar como compreensão "da palavra e do mundo" (o texto e o contexto), por exemplo, se converte em praxis transformadora, porque, ao tomar conhecimento daquilo que o rodeia, o homem passa da esfera mecânica e passiva de apreensão da realidade para a dimensão crítica e participativa, na qual a consciência aflora como fruto do processo de ação-reflexão.

A definição de Desenvolvimento Humano sugerida por Vigotski, sustentada pela interação das instâncias psicológicas, antropológicas e orgânicas, permite vislumbrar o sujeito em sua complexidade. Ademais, o conceito de Zona de Desenvolvimento Proximal, definido também por ele, admite como ponto de partida, 
acreditar que somos dotados de potencialidades que, ao serem estimuladas, favorecem o aparecimento de manifestações imprevisíveis, inesperadas, alimento de nossa criatividade.

A ação sócio-educativa baseada na interlocução Freire-Vigotski, advém do diálogo acerca dos problemas das pessoas, favorecendo a que elas expressem o mundo em que vivem a partir do seu modo de concebê-lo. E, nesta interação, tomar consciência do que é vivido pelo próprio grupo e a realidade concreta do dia-a-dia que o cerca. Assim, a ação sócio-educativa se efetiva através de dois princípios: o da realidade objetiva e o do interesse individual/coletivo. Toda ação educativa pretende alcançar um fim, um objetivo que não permite a neutralidade.

Os principais problemas da educação não são exclusivamente questões pedagógicas, mas também questões políticas.

No caso dos jovens, quando começam a não ir mais para a escola, quando a terminam mais mal do que bem e não têm perspectivas nem formativas, nem de trabalho, quando em seu grupo social restrito vivem como algo "normal" o estar sem fazer nada, isto gera um cotidiano isento de normas, de responsabilidade e de preocupações.

Quando estes adolescentes e jovens, pontualmente algum(a) menor, interiorizam, estas formas de funcionamento em que se sentem livres das normas e limites do sistema social, sem se dar conta de que outras normas e outros limites estão movendo suas atuações, quando a rua se converte para eles(as) em um espaço enganoso de liberdade, educadores e educadoras, temos que recuperar a rua como um espaço livre e educativo.

Educativo não no sentido que eles rechaçam, mas no de recuperar e reconstruir aqueles valores positivos, como a solidariedade e o companheirismo, que

\section{REFERÊNCIAS}

Arquero, M. (1998). Educación de calle: hacia un modelo de intervención en marginación juvenil. 2.ed. Madrid: Editorial Popular.

Jares, X.R. (1999). Educación para la paz: su teoría e práctica. 2.ed.Madrid: Editorial Popular.

Lara, I. S. \& Silva, M. M. (2000). Por uma pedagogia para a não violência. Porto: Profedições Ltda. vão sendo esquecidos, ou quando existem, estão sendo manipulados pelas circunstâncias do próprio contexto; de torná-los conscientes da realidade "tão pouco livre" que vivem; de viabilizar alternativas para suas necessidade, carências e problemáticas. Mas, fundamentalmente, no sentido de conhecerem possibilidades diferentes de relação e atuação, em que é possível expressarem suas opiniões, transformando-se assim em protagonistas de suas próprias vidas.

Deste modo, um dos passos para que o jovem se perceba socialmente produtivo é permitindo que participe do mercado de trabalho a partir de sua profissionalização. Entretanto, para que esta escolha seja valorizada, ela deve estar vinculada ao interesse do próprio jovem, ao respeito por sua opção de carreira a seguir, e não pela imposição do adulto que não quer mais lhe ver como um indolente. Só assim, eles estarão reconhecendo a existência de suas potencialidades, se apropriando de suas capacidades, seus afetos, modos de comportamento mais positivos, mais humanos, que transcendem a sua pessoa e o seu entorno.

A perspectiva preventiva da ação sócio-educativa se faz a partir do momento em que é possível utilizar outras formas de se relacionar, de atuar e participar, ocorrendo uma leitura nova e positiva da bagagem pessoal que cada um traz consigo.

Em resumo, esta ação quando pretende estimular as potencialidades do jovem, despertando e favorecendo seu papel de protagonista

Constitui o momento do processo educativo no qual se vão traçar objetivos educativos que impliquem em responsabilidade, organização, normas e limites na convivência, no compartilhar ... e tudo isto com a finalidade de que descubram outras experiências que lhes façam sentir-se pessoas com capacidade de opção.

Morin, E. (1996). Ciência com consciência. Rio de Janeiro: Bertrand Brasil.

Morin, E. (2000). Os sete saberes necessários à educação do futuro. São Paulo: Cortez.

Ortiz, F. C. \& Ortiz, R.P. (20001). Amor vs amor. Cuba: Ed. Puebloy Educación.

Osorio, A. R. (2001). Conocer para transformar. Encarte. Barcelona: Cisspraxis. 
Vygotsky, L. (1988). A formação social da mente: o desenvolvimento dos processos psicológicos superiores. São Paulo: Martins Fontes. 